\title{
Dislocation Characterization by the Direct- fitting/modified Williamson-Hall (DF/mWH) Method in Ultra-low Carbon Martensitic Steel
}

\author{
Takuro Masumura ${ }^{1)^{*}}$, Setsuo TAKAKi ${ }^{1)}$ and Toshihiro TsuchiYAmA ${ }^{1,2)}$ \\ 1) Research Center for Steel, Kyushu University \\ 2) Department of Materials Science and Engineering, Kyushu University
}

Abstract: The Williamson-Hall (WH) plots are the basic approach for the dislocation characterization. However, the elastic anisotropy affects full width at half maximum in diffraction peaks and this makes the dislocation characterization difficult. In order to correct the effect of elastic anisotropy, Ungár developed a unique methodology using the contrast factor, so called the modified Williamson-Hall (mWH) method. On the other hand, authors developed a new methodology termed as "direct-fitting (DF) method" in which the elastic anisotropy is corrected directly applying the correction parameter; $\omega_{\mathrm{hkl}}$. By the DF method, reliable values are obtained for the parameter $\alpha$ which contains an information of crystallite size. In this paper, the $\alpha$-value obtained by the DF method was applied to the mWH method and the dislocation characterization was performed in an ultra-low carbon martensitic steel (Fe-18\%Ni alloy) with cold rolling up to $20 \%$ thickness reduction. It was found that high dislocation density $\rho$ of $2.1 \times 10^{15} / \mathrm{m}^{2}$ is obtained in as-quenched specimen and the cold rolling does not give significant effect on dislocation density $\rho$. However, the parameter $\varphi$ obtained by the mWH method changes markedly by charging small amount of cold rolling. As a result, the parameter $A$, that depends on the values of $\rho$ and $\varphi$, changes markedly by charging small amount of cold rolling: $A=0.77$ in as-quenched specimen but $A=0.60$ in specimens with cold rolling. This result indicates that the dislocation arrangement has been changed from homogeneous to inhomogeneous distribution by cold rolling.

Keywords: Williamson-Hall plots; elastic anisotropy; direct-fitting/modified Williamson-Hall method; dislocation arrangement; dislocation density; screw component; ultra-low carbon martensitic steel.

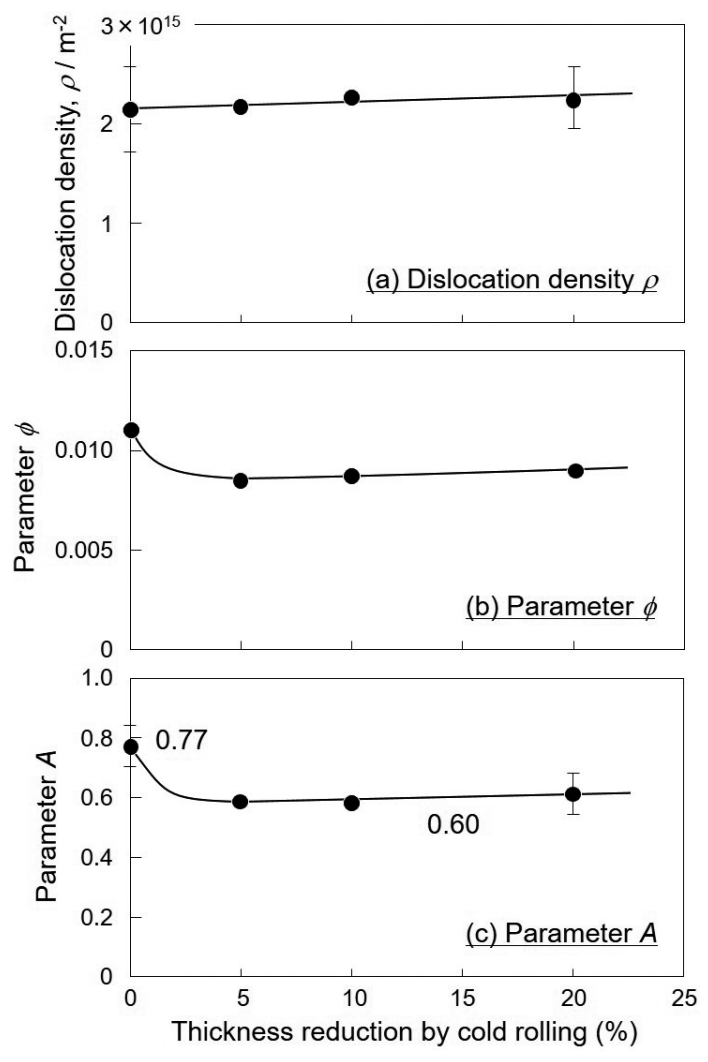

Received on May 14, 2019 ; Accepted on Oct. 11, 2019

* Corresponding author. E-mail : masumura@zaiko.kyushu-u.ac.jp, Address : Kyushu University, 744 Motooka Nishi-ku Fukuoka 819-0395 


\section{Direct-fitting/modified Williamson- Hall (DF/mWH) 法による極低炭素 マルテンサイト鋼の転位解析}

\author{
増村 拓朗 ${ }^{1)^{*}} \cdot$ 高木 節雄 ${ }^{1)} \cdot$ 土山 聡宏 ${ }^{1,2}$ \\ Dislocation Characterization by the Direct-fitting/modified \\ Williamson-Hall (DF/mWH) Method in Ultra-low Carbon \\ Martensitic Steel \\ Takuro MASUmura, Setsuo TAKAKI and Toshihiro TsUchiYama
}

\section{1. 緒言}

加工した金属やマルテンサイト鋼のように多量の転位を内 蔵した材料では, その転位密度が力学特性に大きな影響を及 ぼす。近年では量子線ラインプロファイル解析である modified Williamson-Hall/Warren-Averbach (mWH/WA) 法 ${ }^{1)}$ による転位 解析が広く用いられているが, 著者らはdirect-fitting/modified Williamson-Hall (DF/mWH) 法 ${ }^{2)}$ にっって, より簡便に転位密 度を導出できることを示した。ただし, $\mathrm{DF} / \mathrm{mWH}$ 法を適用する には後述するパラメーター $A$ を鋼種ごとに求めておく必要があ る。本研究では, マルテンサイト鋼の転位密度評価を $\mathrm{DF} / \mathrm{mWH}$ 法で行えるようにするために, 極低炭素の Fe-18\% Ni 合金を用い て, 焼入材ならびに $20 \%$ まで圧延した加工材に $\mathrm{DF} / \mathrm{mWH}$ 法な らびに $\mathrm{mWH} / \mathrm{WA}$ 法を適用して転位解析を行い, マルテンサイ 卜鋼におけるパラメーターAの值を求めた。

\section{2. 解析方法}

Williamson and HallはX線回折ピークの半価幅の情報から 転位密度を見積もる方法を提唱した ${ }^{3)}$ 。X 線の波長を $\lambda$, 結晶 面 \{hkl の回折角と半価幅をそれぞれ $\theta_{\mathrm{hkl}}$ と $\beta_{\mathrm{hkl}}[\mathrm{rad}$.$] とすると,$ それぞれの結晶面に対応してパラメーター $K_{\mathrm{hkl}}\left(=2 \sin \theta_{\mathrm{hkl}} / \lambda\right)$ と $\Delta K_{\mathrm{hkl}}\left(=\beta_{\mathrm{hkl}} \cos \theta_{\mathrm{hkl}} / \lambda\right)$ を決定できる。結晶方位に依存した弾性 異方性が無ければ, パラメーター $K_{\mathrm{hk} 1}$ と $\Delta K_{\mathrm{hk} 1}$ の間には直線関係 が成立し, 両者の関係は次式で表される ${ }^{3)}$ 。

$\Delta K_{\mathrm{hkl}}=\alpha+\varepsilon K_{\mathrm{hkl}}$ $\alpha$ は結晶子の大きさに依存したパラメーター, $\varepsilon$ は転位密度や転 位の分布, 転位の性質に依存したミクロひずみと呼ばれるパラ メーターである。しかし, 多くの金属には弾性異方性があるため, $K_{\mathrm{hkl}}$ と $\Delta K_{\mathrm{hkl}}$ の関係は不規則な分布となり, 直線関係は得られな い。

弾性異方性を補正する方法として, 著者らは, 次式で定義さ
れるパラメーター $\omega_{\mathrm{hkl}}$ を用いた direct-fitting (DF) 法という手法 を提案した ${ }^{4)}$ 。

$$
\omega_{\mathrm{hkl}}=E_{\mathrm{hkl}} / E_{0}
$$

$E_{0}$ はひずみを一定と仮定したVoigt モデルで得られる基準ヤン グ率 $\left(E_{0}=226.3 \mathrm{GPa}\right)^{4,5)}, E_{\mathrm{hkl}}$ は各多結晶金属の $\{\mathrm{hkl}\}$ 面に対応 し, 補正係数 $\omega_{\mathrm{hk}}$ を与えるための任意のヤング率 ${ }^{4}$ である。各結 晶面の $\omega_{\mathrm{hkl}}$ を用いて次式で弾性異方性を補正すると, 良好な直 線関係が得られることを確認している ${ }^{4)}$

$\Delta K_{\mathrm{hkl}}=\alpha+\varepsilon\left(K_{\mathrm{hkl}} / \omega_{\mathrm{hkl}}\right)$.

一方, Ungár and Borbélyは, 次式で定義されるコントラスト ファクター $C_{\mathrm{hk} 1}$ を用いて弾性異方性を補正することを提唱し た ${ }^{1)}$ 。

$$
C_{\mathrm{hkl}}=C_{\mathrm{h} 00}\left(1-q \Gamma_{\mathrm{hkl}}\right)
$$

$C_{\mathrm{h} 00}$ は $\{\mathrm{h} 00\}$ 面に対応するコントラストファクター, $q$ は $C_{\mathrm{hk}}$ 值の 結晶方位依存性の大きさを示す係数, $\Gamma_{\mathrm{hkl}}$ は次式で与えられる 方位パラメーターである。

$$
\Gamma_{\text {hkl }}=\left(\mathrm{h}^{2} \mathrm{k}^{2}+\mathrm{k}^{2} \mathrm{l}^{2}+\mathrm{l}^{2} \mathrm{~h}^{2}\right) /\left(\mathrm{h}^{2}+\mathrm{k}^{2}+\mathrm{l}^{2}\right)^{2} \quad\left(0 \leq \Gamma_{\mathrm{hkl}} \leq 1 / 3\right)
$$

$C_{\mathrm{h} 00}$ と $q$ の值は, 転位のらせん成分の割合 $S(0 \leqq S \leqq 1)$ に依存 して変化し，それぞれ次式で与えられる。

$$
\begin{aligned}
& C_{\mathrm{h} 00}=C_{\mathrm{h} 00}^{E}+S\left(C_{\mathrm{h} 00}^{S}-C_{\mathrm{h} 00}^{E}\right) \\
& q=q^{E}+S\left(q^{S}-q^{E}\right) .
\end{aligned}
$$

$C_{\mathrm{h} 00}^{\mathrm{E}}, C_{\mathrm{h} 00}^{\mathrm{S}}$ ならびに $q^{\mathrm{E}}, q^{\mathrm{S}}$ は, 完全な刃状転位とらせん転位に 対応した值であり, 金属の結晶構造と弾性スティフネスで決ま る材料定数である ${ }^{6)}$ 。弾性異方性の補正には, 次式で表される modified Williamson-Hall (mWH) の式が用いられる1)。

$$
\Delta K_{\mathrm{hkl}}=\alpha+\varphi K_{\mathrm{hkl}} \sqrt{C_{\mathrm{hkl}}}+O K_{\mathrm{hkl}}^{2} C_{\mathrm{hkl}}
$$

$\varphi$ は, 転位密度 $\rho$ と転位の分布状態で決まるパラメーター $A^{7)}$, 転 位のBurgersべクトルの大きさ $b(0.248 \mathrm{~nm})$ で決まるパラメー ターであり，次式で与えられる。

$$
\varphi=(\pi / 2)^{1 / 2} A b \sqrt{\rho} \text {. }
$$

パラメーター $\varphi$ の值は, 次に述べる $\mathrm{mWH}$ 法で求められるので, パラメーターAの值が分かっていれば, 次式で $\rho$ の值を決定で きる。

$$
\rho=2 \varphi^{2} /\left(\pi A^{2} b^{2}\right)
$$

10〜80\%の冷間圧延を施した鉄については, $A \fallingdotseq 0.5$ ということ が分かっているので 2,7$)$, 一般的なフェライト鋼については, 式 （10）を用いて転位密度を見積もることができる。

一方, 式 (8) については, 右辺第3 項は大変小さい ${ }^{8)}$ ので無 視した後, $\alpha$ を左辺に移項して式 (4) を代入し, 2 乗することで 次式が得られる9)。

$$
\left(\Delta K_{\mathrm{hkl}}-\alpha\right)^{2} / K_{\mathrm{hkl}}^{2}=\varphi^{2} C_{\mathrm{h} 00}\left(1-q \Gamma_{\mathrm{hkl}}\right)
$$
この式において, 左辺の值と $\Gamma_{\mathrm{hkl}}$ の間には直線関係が成立する ことが分かる。 $\mathrm{mWH}$ 法では, $\alpha$ に任意の值を代入して, 左辺と

2019年5月14日受付２019年10月11日受理（Received on May 14, 2019 ; Accepted on Oct. 11, 2019）

1）九州大学鉄鋼リサーチセンター (Research Center for Steel, Kyushu University)

2）九州大学大学院工学研究院材料工学部門 (Department of Materials Science and Engineering, Kyushu University)

* Corresponding author. E-mail : masumura@zaiko.kyushu-u.ac.jp, Address : Kyushu University, 744 Motooka Nishi-ku Fukuoka $819-0395$ 
$\Gamma_{\mathrm{hk}}$ の直線関係が最良となるように $\alpha$ 值を決定し, 決定した直 線からq值を求め, 式 (7) に基づいて $S$ 值が決定される。しか し, DF法を適用すれば前もって $\alpha$ 值を正確に求めることができ るので，その值を式 (11) に代入することにより一義的に左辺と $\Gamma_{\text {hkl }}$ の関係を決定できる。この手法を $\mathrm{DF} / \mathrm{mWH}$ 法というう ${ }^{2)}$ 。 DF/ $\mathrm{mWH}$ 法で得た直線の $\mathrm{x}$ 切片から $q$ 值, $\Gamma_{\mathrm{hkl}}=0$ に対応するy切 片値から $\varphi^{2} C_{\mathrm{h} 00}$ の值を決定できる。式 (7) にq值を代入して $S$ 值が得られ, 式 (6) にS值を代入して $C_{\mathrm{h} 00}$ の值が求まるので, $\varphi^{2} C_{\mathrm{h} 00}$ の值から $\varphi$ 值を決定できる。

式 (10) から転位密度 $\rho$ を求めるには, $A$ 值をあらかじめ決定 しておく必要があるため, mWH/WA 法による転位密度解析を 行った。

$$
\begin{aligned}
& \ln A(L) \cong \ln A^{S}(L)-Y(L)\left(K_{\mathrm{hkl}}^{2} C_{\mathrm{hkl}}\right)+Q\left(K_{\mathrm{hkl}}^{4} C_{\mathrm{hkl}}^{2}\right) \ldots \ldots \ldots \ldots \ldots \ldots \ldots \\
& Y(L) / L^{2}=-\left(\pi b^{2} \rho / 2\right) \ln R e+\left(\pi b^{2} \rho / 2\right) \ln L \ldots \ldots \ldots \ldots \ldots \ldots \\
& \ldots
\end{aligned}
$$

ここでLはフーリエ長さ, $A(L)$ は回折ピークをフーリエ変換し たときのフーリ工係数の実部, $A^{S}(L)$ はその結晶子サイズ成分, $R e$ は転位の有効応力場半径, $Q$ は $\left(K_{\mathrm{hkl}}^{4} C_{\mathrm{hkl}}^{2}\right)$ の高次項である。 また, $C_{\mathrm{hkl}}$ は $\mathrm{mWH}$ 法で得られた值を用いる。詳細な解析手法の 説明は文献 1,7,10) を参考にされたい。最終的には式 (13)にある転 位密度 $\rho$ や Reの厳密解を本手法により求めることができる。

本研究では, $\mathrm{DF} / \mathrm{mWH}$ 法でパラメーター $\varphi, \mathrm{mWH} / \mathrm{WA}$ 法で転 位密度 $\rho$ を求め, 式 (9) に基づいて両者の関係からパラメーター $A$ の值を決定する。

\section{Direct-fitting 法による弾性異方性の補正}

実験に使用した材料は真空溶解で作製した Fe- $17.8 \% \mathrm{Ni}-$ $0.001 \% \mathrm{C}$ 合金であり, $900^{\circ} \mathrm{C}-30 \mathrm{~min} の$ 溶体化処理を施したのち 水冷し, 室温ではラスマルテンサイトの単一組織となっているこ とをEBSDにより確認した。そのあと, 加工率が 5\%, 10\%, 20\% になるように圧延して加工材を作製した。X線回折実験には $\mathrm{Cu}-\mathrm{K} \alpha$ (波長 : $0.15418 \mathrm{~nm}$ ) を用い, 検出器の回転速度は 0.003 $\mathrm{deg} / \mathrm{s}$ とした。装置関数補正は, $\mathrm{LaB}_{6}$ (No. : SMR660c, NIST製) を使用してVoigtプロファイル解析法に基づいて行った ${ }^{11}$ 。試料 は, 処理を済ませた板材から $15^{1} \times 15^{\mathrm{w}} \mathrm{mm}$ の寸法に切り出し, サ ンドペーパーで表面を平坦にしたのち, 研磨の影響 ${ }^{12}$ を除去す

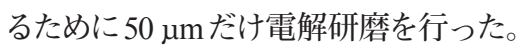

焼入材ならびに $20 \%$ までの圧延を施した試料について, X線 回折実験により得られたパラメーター $K_{\mathrm{hkl}}$ と $\Delta K_{\mathrm{hkl}}$ の関係を Fig.1
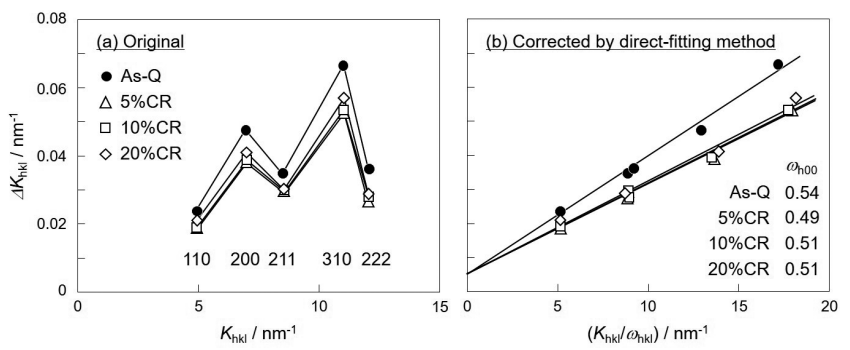

Fig. 1. Original (a) and corrected (b) Williamson-Hall plots in ultra-low carbon martensitic steel $(\mathrm{Fe}-18 \% \mathrm{Ni})$. (a)に示す。 $\{220\}$ 面からの回折強度は極端に弱いため, ここで は削除している。 $\Delta K_{\mathrm{hkl}}$ の值は格子ひずみに依存して変化する

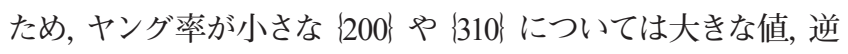
にヤング率が大きな $\{22\}$ については小さな值となる傾向にあ る。マルテンサイト鋼については, 加工の有無にかかわらずデー タのばらつきが大きい,つまり弾性異方性が大きいことが分か る。ここで注目すべき点は, 焼入材と加工材でデータの分布が 異なっていることであり, 僅か $5 \%$ の加工を施すだけでWHプ ロットのデータの分布が変化している。DF法の詳細なプロセ ス $^{2,4)}$ は省略するが, 弾性異方性の補正をパラメーター $\omega_{\mathrm{bk}} に よ$ り行ったWHプロットをFig.1 (b) に示す。図中には補正に使用 した各試料の $\omega_{\mathrm{h} 00}$ の值を記しており, 他の回折面の $\omega_{\mathrm{hkl}}$ は $\omega_{\mathrm{h} 00}$ が分かっていれば計算できる ${ }^{4,5}$ 。この図においても, 焼入材と 加工材で直線の傾きが大きく異なっていることが分かる。つま り, $5 \%$ という僅かなひずみを加えただけでミクロひずみの值が 低下し，光れ以上の加工を加えてもミクロひずみはほとんど変 化しない。ただし，切片值のパラメーター 響はほとんどなく, ほぼ同じ值となっている $\left(\alpha \fallingdotseq 0.005 \mathrm{~nm}^{-1}\right)$ 。

\section{Direct-fitting/modified Williamson-Hall法 による解析結果}

$m W H$ 法に扑いては, 転位のらせん成分 $S$ を決定する際に弾 性スティッフネス $c_{11}, c_{12}, c_{44}$ の值が必要である。幸い, Fe- $\mathrm{Ni}$ 系 合金についてはこれらの值が報告されており ${ }^{13)}, \mathrm{Fe}-18 \% \mathrm{Ni}$ 合金 については, $c_{11}=180.0 \mathrm{GPa}, c_{12}=106.4 \mathrm{GPa}, c_{44}=114.6 \mathrm{GPa}$ いう值になる。これらの值を用いてUngárらが提唱した式のによ りコントラストファクター $C_{\mathrm{h} 00}$ とパラメーター $q$ を求めると, 刃状 転位については $C_{\mathrm{h} 00}{ }^{\mathrm{E}}=0.295, q^{\mathrm{E}}=1.610$, らせん転位について は $C_{\mathrm{h} 00}{ }^{\mathrm{S}}=0.330, q^{\mathrm{S}}=2.694$ という結果が得られた。DF法で得ら れた $\alpha$ 值を式 (11) に代入した結果を Fig.2に示す。ここでも, 焼 入材と加工材では全く異なった結果が得られている。直線の傾 きから得られるパラメーターSの值は, 焼入材については 0.82 , 加工材については 0.90 0.92 とほぼ一定の值であり, マルテン サイト変態によりらせん成分の大きな転位が導入されているこ とが分かった。 $S$ 值が分かれば式 (6)により $C_{\mathrm{h} 00}$ の值を決定でき

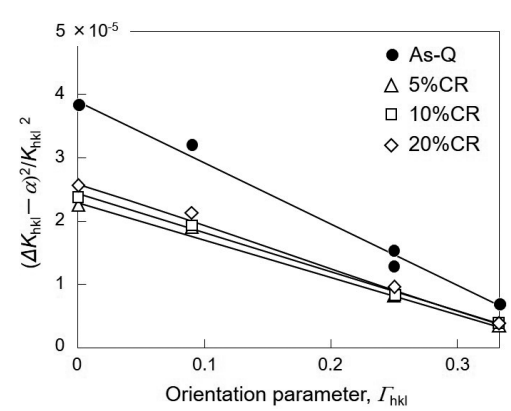

Fig. 2. Relation between the values of $\left(\Delta K_{\mathrm{hkl}}-\alpha\right)^{2} / K_{\mathrm{hkl}}{ }^{2}$ and orientation parameter $\Gamma_{\text {hkl }}$ in ultra-low carbon martensitic steel $(\mathrm{Fe}-18 \% \mathrm{Ni})$. 
る。さらに, $\Gamma_{\mathrm{hkl}}=0$ における切片值は $\varphi^{2} C_{\mathrm{h} 00}$ なので, その值から $\varphi$ 值を求めることができる。

$\varphi$ 值については, 式 (9) から分かるように転位密度 $\rho$ とパラ メーターAに依存して変化する可能性がある。そこでまず, 転位 密度に及ぼす加工の影響を調査した。Fig.3に, mWH/WA 法に おける $\ln L$ と $Y(L) / L^{2}$ の関係を示す。ここでは, $5 \%$ 圧延の影響 を示すために, 焼入材ならびに $5 \%$ 加工材について得られた結 果を示している。転位密度 $\rho$ につては, 眓中に破線で示した 直線の傾き $\eta$ から次式により求めることができる。

$$
\rho=2 \eta /\left(\pi b^{2}\right)
$$

焼入材と $5 \%$ 加工材について $\eta$ 值を比較した結果，いずれもほ ぼ同じ值 $(\eta \fallingdotseq 0.00021)$ となることを確認できた。この結果は, $5 \%$ の冷間圧延を施しても転位密度がほとんど変化しないこと を示唆している。

Fig.4は, mWH/WA法で得られた転位密度 $\rho^{14)}, \mathrm{DF} / \mathrm{mWH}$ 法 で得られたパラメーター て得られたパラメーターAの值を圧延率との関係で示している。 焼入材の転位密度は $2.1 \times 10^{15} / \mathrm{m}^{2}$ と高く，その值は圧延率の増 加とともにわずかに大きくなる傾向を示すが, 加工に伴う急激 な変化は見られない。それに対して $\varphi$ 值は, $5 \%$ 圧延によって急

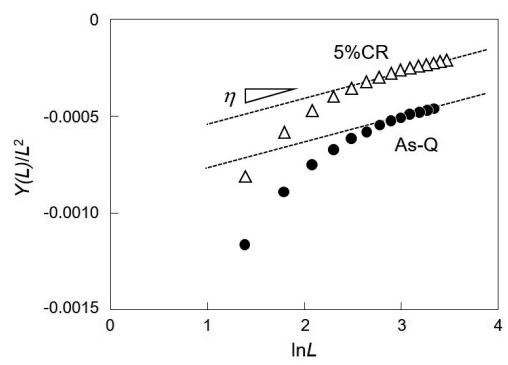

Fig. 3. Results obtained by modified Warren-Averbach method in as quenched specimen and 5\% cold rolled specimen.

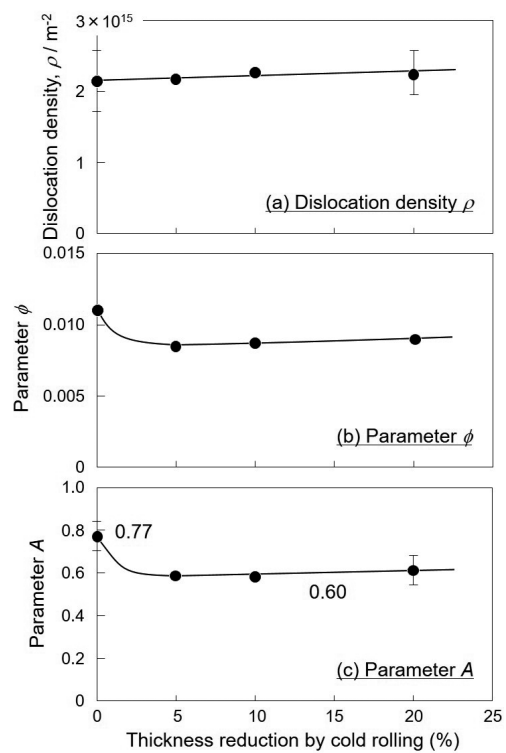

Fig. 4. Changes of dislocation density $\rho$ (a), parameter $\varphi$ (b) and parameter $A(\mathrm{c})$ with cold rolling in ultra-low carbon martensitic steel $(\mathrm{Fe}-18 \% \mathrm{Ni})$.
激に低下した後, 加工率の増加とともにわずかに増大する傾向 を示す。なお, $\varphi$ 值のエラーバーはプロットに隠れる程度に小さ い。一方, $A$ 值については, 焼入材で 0.77 程度の值が得られるの に対して, 加工材では加工率とは無関係に 0.60 という低い值に なっている。パラメーターAは転位分布の均一性に対応してお り, 転位の分布が均一なほど大きな值となる。つまり, $5 \%$ の圧 延で $A$ 值が急激に低下したということは，わずかな加工によっ て転位の再配列が起こり，転位の分布が不均一になったこと を示唆している。 $A$ 值の変化は, 著者らがすでに報告した $M$ 值 (mWH/WA 法により得られる転位配列パラメーター) の変化と もよく一致している ${ }^{14)}$ 。炭素添加や焼戻しによって $A$ 值がじの ように変化するかについては今後の課題として残されているが, 少なくとも炭素を含まない焼入れた状態のマルテンサイト鋼に ついては $A \fallingdotseq 0.77$, 加工したマルテンサイトについては $A \fallingdotseq 0.60$ と置いて, 式 (10) に基づいて転位密度を見積もることができる であろう。

\section{謝辞}

本研究は, JSPS科研費JP15H05768の支援を受けて行われた ものである。なお, 研究の一部は, 日本鉄鋼協会「鉄鋼のミクロ 組織要素と特性の量子線解析研究会」のもとで実施された。

\section{文献}

1 ) T.Ungár and A.Borbély: Appl. Phys. Lett., 69(1996), 3173. https:// doi.org/10.1063/1.117951

2 ) S.Takaki, T.Masumura and T.Tsuchiyama: ISIJ Int., 59(2019), 567. https://doi.org/10.2355/isijinternational.ISIJINT-2018-623

3 ) G.K.Williamson and W.H.Hall: Acta Metall., 1(1953), 22. https://doi. org/10.1016/0001-6160(53)90006-6

4 ) S.Takaki, F.Jiang, T.Masumura and T.Tsuchiyama: ISIJ Int., 58(2018), 769. https://doi.org/10.2355/isijinternational.ISIJINT-2017-642

5 ) S.Takaki, T.Masumura, F.Jiang and T.Tsuchiyama: J. Soc. Mater. Sci. Jpn., 67(2018), 855 (in Japanese). https://doi.org/10.2472/jsms.67.860

6 ) T.Ungár, I.Dragomir, Á.Révész and A.Borbély: J. Appl. Crystallogr., 32(1999), 992. https://doi.org/10.1107/S0021889899009334

7 ) S.Takaki, T.Masumura, F.Jiang and T.Tsuchiyama: Tetsu-to-Hagané, 104(2018), 683 (in Japanese). https://doi.org/10.2355/tetsutohagane. TETSU-2018-054

8 ) S.Takaki, T.Masumura and T.Tsuchiyama: ISIJ Int., 58(2018), 2354. https://doi.org/10.2355/isijinternational.ISIJINT-2018-517

9 ) T.Masumura, S.Takaki, F.Jiang and T.Tsuchiyama: Tetsu-to-Hagané, 104(2018), 717 (in Japanese). https://doi.org/10.2355/tetsutohagane. TETSU-2018-095

10) S.Sato, K.Wagatsuma, M.Ishikuro, E.-P.Kwon, H.Tashiro and S.Suzuki: ISIJ Int., 53(2013), 673. https://doi.org/10.2355/ isijinternational.53.673

11) Th.H. de Keijser, J.I.Langford, E.J.Mittermeijer and A.B.P.Vogels: J. Appl. Crystallogr., 15(1982), 308. https://doi.org/10.1107/ S0021889882012035

12) F.Jiang, K.Hirata, T.Masumura, T.Tsuchiyama and S.Takaki: ISIJ Int., 58(2018), 376. https://doi.org/10.2355/isijinternational. ISIJINT-2017-578

13) D.K.Chaudhuri, P.A.Ravindran and J.J.Wert: J. Appl. Phys., 43(1972), 778. https://doi.org/10.1063/1.1661280

14) D.Akama, T.Tsuchiyama and S.Takaki: ISIJ Int., 56(2016), 1675. https://doi.org/10.2355/isijinternational.ISIJINT-2016-140 